\title{
Galeri Mural Dan Graffiti Dengan Penerapan Konsep EksPresi Dalam Arsitektur Di Kota Surakarta
}

\author{
Brilly Prayudha Sudibyo, MDE Purnomo, Rachmadi Nugroho \\ Program Studi Arsitektur \\ Fakultas Teknik \\ Universitas Sebelas Maret Surakarta \\ Email: prayudhabrilly@gmail.com
}

\begin{abstract}
Gallery of Murals and Graffiti planning and designing in Surakarta motivated by the issue of urban art, especially murals and graffiti growing in Surakarta. The need for container murals and graffiti that can accommodate, develop, and provide education and information on the value of urban art itself. The existence of Surakarta as a center of art and culture add more motivated issue to planning and designing the Gallery of Murals and Graffiti. The goal is to plan and design a Gallery of Murals and Graffiti that can accommodate the expression of urban art also functions as an alternative public space for the city of Surakarta with the application of the concept of Expression in Architecture. Design issue is how the concept of Expression in Architecture which includes site selection, layout, orientation, circulation, use of material, color selection, and expression forms and facades can be applied to the Gallery of Mural and Graffiti. Design method used is by applying Expression in Architecture and combined with design standards gallery. Application concept of Expression in Architecture on Gallery of Murals and Graffiti such as the design of the site selection, layout, orientation, circulation, use of material, color selection, as well as the shapes and facades expression in building system.
\end{abstract}

Keywords: Form, Facade, Materials, Colors

\section{PENDAHULUAN}

Kesenian dan kebudayaan merupakan salah satu media bagi seseorang, masyarakat, atau kelompok tertentu untuk berhubungan dan berinteraksi dengan individu atau pun dengan masyarakat lain. Keberadaan kesenian dan kebudayaan dari masa ke masa juga mengalami perkembangan guna beradaptasi dengan keadaan sosial masyarakat. Kota Surakarta yang duduk sebagai salah satu pusat kesenian dan kebudayaan Jawa Tengah juga mengalaminya. Berbagai penyesuaian dan perubahan terhadap masa kini dilakukan oleh berbagai lapisan masyarakat. Seiring dengan perkembangan kegiatan masyarakat dalam berkesian, selain seni rupa, seni tari, seni teater, seni wayang, dan seni musik, di Kota Surakarta juga berkembang seni urban, khususnya mural dan graffiti.

Saat ini telah muncul fenomena yang menarik bagi sekelompok orang (masyarakat urban), yaitu berkembangnya komunitaskomunitas kesenian yang bertemakan street art dan youth culture oleh para remaja. Beberapa komunitas seni mural dan graffiti yang ada di Kota Surakarta menurut RHARHARHA, Andi dalam Begins by Connceting, Street Art is Networking, 2013, antara lain adalah Tugitu Unite, Techno Street Art Terror, dan Nodakota. Selain komunitas-komunitas tersebut, juga ada seniman yang bergerak secara independent. Tidak seperti di Kota Yogyakarta, mural dan graffiti di Kota Surakarta masih dipandang sebelah mata. Kegiatan bombing (melalukan pembuatan mural dan graffiti) masih dilakukan secara diam-diam atau ilegal dan juga masih dianggap sebagai kegiatan yang negatif oleh beberapa kalangan, kecuali kegiatan mural dan graffiti tersebut dilombakan atau melibatkan pihak pemerintah maupun swasta.

Seni mural dan graffiti yang sedang berkembang di kalangan remaja di Kota Surakarta masih belum terwadahi dan masih menggunakan media yang bukan peruntukannya atau semestinya. Oleh karena itu, berdasarkan fenomena-fenomena yang terjadi tersebut, dibutuhkan sebuah wadah 
seni, khususnya untuk seni mural dan graffiti yang dapat menampung, mewadahi, mengembangkan, serta memberi nilai edukasi dan informasi mengenai seni mural dan graffiti. Wadah seni mural dan graffiti ini diperuntukkan bagi para pelaku kegiatan seni tersebut, seperti penikmat seni, pengamat seni, komunitas-komunitas mural dan graffiti, serta wisatawan domestik dan internasional yang datang ke Kota Surakarta.

\section{METODE}

A. Macam dan Teknik Pengumpulan Data

Data yang dikumpulkan yakni data terkait proses perancangan Galeri Mural dan Graffiti, seperti data lokasi dan tapak, data kegiatan di galeri, dan kebutuhan ruang galeri. Selain itu, juga terdapat tinjauan pustaka terkait permassaan galeri, bentuk dan gubahan massa, sistem struktur, sistem utilitas, dan strategi penerapan konsep Ekspresi dalam Arsitektur. Semua data tersebut diperoleh dari tinjauan pustaka serta wawancara kepada pelaku kegiatan.

B. Metode Analisis Data

Analisis perancangan dilakukan dengan mengidentifikasi masalah yang ada pada konsep perancangan Galeri Mural dan Graffiti dengan penerapan konsep Ekspresi dalam Arsitektur yang kemudian digabungkan dengan standar perancangan galeri yang terdapat pada tinjauan teoritis.

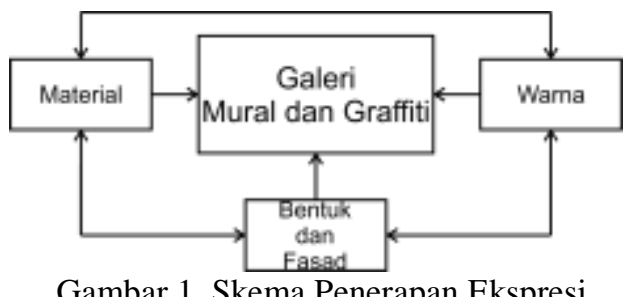

Gambar 1. Skema Penerapan Ekspresi dalam Arsitektur

Penerapan konsep Ekspresi dalam Arsitektur mengutip dari Muchamad dan Ikaputra dalam Seminar Metodologi Riset dalam Arsitektur, 2010, mengacu pada tiga elemen ekspresi, yakni, menggunakan ekspresi bentuk yang mengungkapkan perasaan postif maupun negatif, menggunakan material yang konstruktif berupa kaca, baja, dan dinding beton atau batu bata, dan pemilihan warna pada bangunan (dapat merujuk pada Gambar 1) yang nantinya menjadi image yang melekat pada bangunan tersebut, serta peningkatan performansi yang akan diwujudkan dalam perancangan galeri mural dan graffiti secara holistik, yaitu pada kegiatan, ruang, tapak, massa, struktur, dan utilitas.

\section{ANALISIS}

A. Analisis Peruangan

1. Pengguna

Pengguna terdiri dari:

a. Komunitas mural dan graffiti;

b. Seniman mural dan graffiti;

c. Kurator;

d. Pengelola;

e. Pengunjung;

f. Petugas servis; dan

g. Petugas komersil.

2. Analisis Kebutuhan Ruang

Berikut analisis kebutuhan ruang pada Galeri Mural dan Graffiti:
a. Area utama;
b. Area pengelolaan;
c. Area pendukung;
d. Area penunjang;
e. Area utilitas; dan
f. Area park and ride

B. Analisis Penataan Tapak

1. Analisis Pemilihan Tapak

Tujuan:

Menentukan tapak yang yang tepat untuk perancangan galeri mural dan graffiti.

Kriteria:

a. Berdasarkan RTRW Kota Surakarta Tahun 2011-2031.

b. Terletak di pusat Kota Surakarta.

c. Memiliki orientasi yang baik.

d. Ketersediaan tapak yang cukup dan tidak banyak merubah aau merusak lingkungan.

Hasil: 


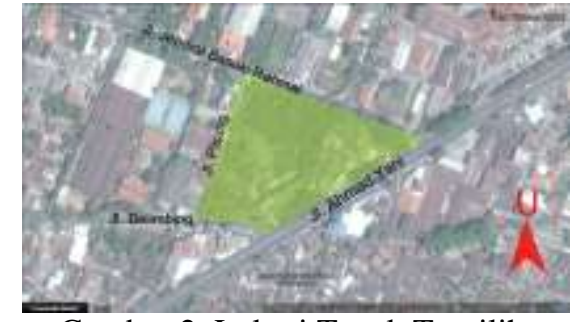

Gambar 2. Lokasi Tapak Terpilih.

Berdasarkan kriteria-kriteria pada analisis pemilihan tapak, tapak yang terpilih berada di Jalan Ahmad Yani, Kelurahan Kerten, Kecamatan Laweyan, Kota Surakarta (lihat Gambar 2).

2. Analisis Tapak Terpilih Tujuan:

Menentukan tapak yang digunakan untuk perancangan Galeri Mural dan Graffiti.

Kriteria:

a. Berdasarkan RTRW Kota Surakarta

Tahun 2011-2031.

b. Memiliki luasan yang cukup.

c. Mudah dicapai oleh pengguna.

d. Memiliki banyak orientasi.

Hasil:

Tapak terpilih memiliki luas area sebesar $\pm 13.251 \quad \mathrm{~m}^{2}$ dengan $\mathrm{KDB}$ maksimal $85 \%$ berdasarkan Perda Kota Surakarta No. 8 Tahun 2009.

Batas-batas tapak (Gambar 3):

Utara: Sunan Hotel, pemukiman warga, dan gudang.

Selatan: Pemukiman warga.

Barat: Pabrik dan pemukiman warga.

Timur: Jalan Ahmad Yani dan pemukiman warga.

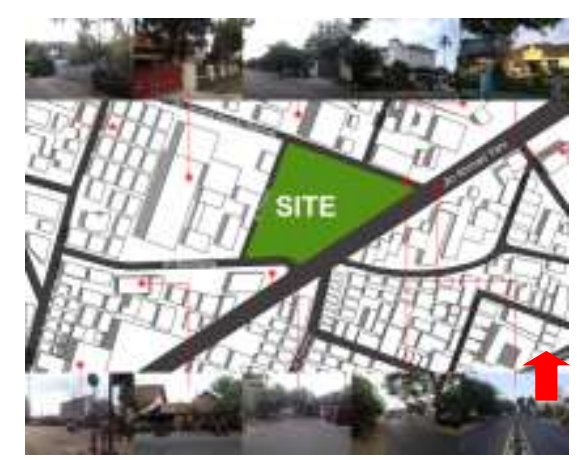

Gambar 3. Tapak dan Batas-Batas Tapak.

Potensi tapak: a. Tapak terpilih berada di pusat Kota Surakarta, yang termasuk ke dalam area peruntukan pariwisata, budaya, bisnis, dan perdagangan yang sesuai dengan data RTRW Kota Surakarta Tahun 2011-2031.

b. Lokasi tapak sangat strategis, berada di jalan protokol Kota Surakarta, dan mudah diakses dari segala arah.

c. Lokasi tapak yang dekat dengan pemukiman warga.

3. Analisis Pola Pencapaian

Tujuan:

Menentukan pola pencapaian menuju tapak berdasarkan kriteria-kriteria.

Kriteria:

a. Kemudahan akses.

b. Sirkulasi lalu lintas sekitar tapak.

c. Pertimbangan keamanan akses ke dalam dan ke luar tapak.

Hasil:

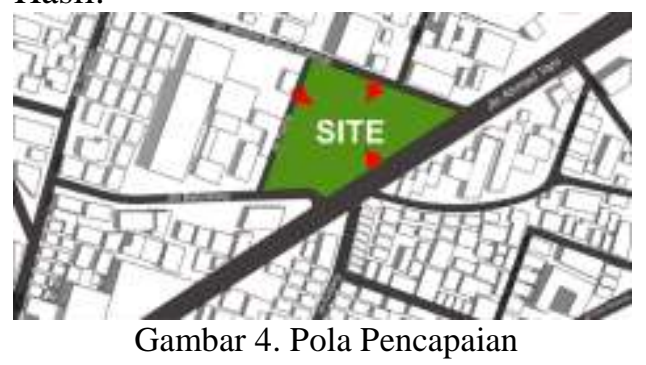

Main Entrance (ME) berada pada timur tapak, digunakan untuk akses masuk kendaraan umum dan pribadi, serta pejalan kaki dari Jalan Ahmad Yani (Gambar 4).

Side Entrance (SE) berada pada utara dan barat tapak, digunakan sebagai akses masuk kendaraan pribadi, umum, dan juga servis (Gambar 4).

4. Analisis View dan Orientasi

Tujuan:

Menentukan orientasi dan view bangunan.

Kriteria:

a. Letak point of view terlihat jelas oleh pengguna.

b. Arah pandang pengunjung dari luar ke dalam tapak.

c. Akses menuju tapak.

Hasil: 


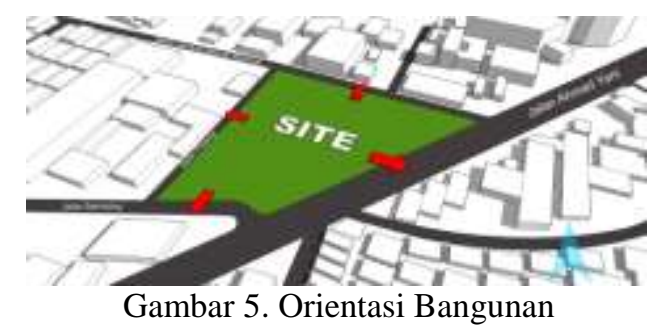

a. Orientasi utama bangunan menghadap ke view utama, yakni Jalan Ahmad Yani (Gambar 5).

b. Poin kedua direncanakan bangunan, dari sudut pandang Jalan Jendral Basuki Rahmat, tidak membutuhkan bentuk yang atraktif karena poin ini bukan merupakan main entrance.

c. Area servis diletakkan pada bagian utara tapak yang memiliki jalan lingkungan.

5. Analisis Klimatologi

Tujuan:

Menentukan respons bangunan terhadap iklim, khususnya matahari dan angin.

Kriteria:

a. Mengoptimalkan kualitas sinar matahari dan angin yang berpotensi sebagai pencahayaan dan penghawaan alami.

b. Menghasilkan respons desain yang tepat terhadap kondisi sinar matahari dan kualitas angin pada bangunan. Hasil:

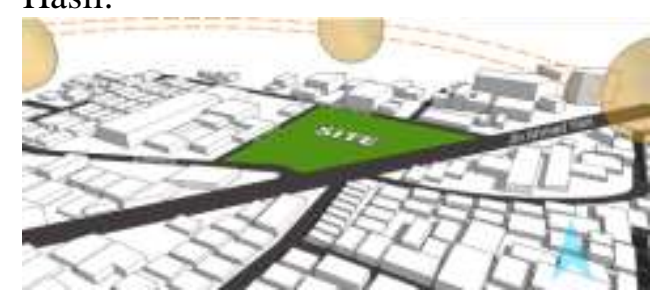

Gambar 6. Pergerakkan Matahari pada Tapak

a. Cahaya matahari yang datang dari arah timur (Jalan Ahmad Yani) merupakan cahaya matahari positif dan berpotensi menjadi symber pencahayaan alami (Gambar 6).

b. Diperlukan barrier sebagai penghalang cahaya matahari berlebih yang datang dari arah barat (Jalan Pisang).

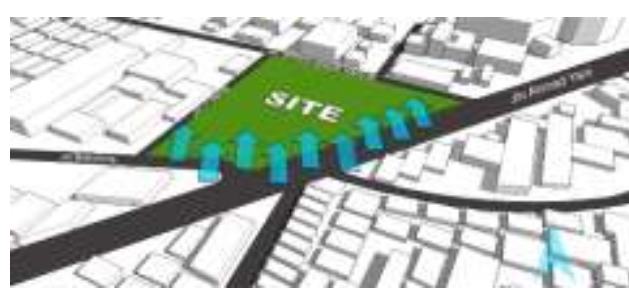

Gambar 7. Pergerakkan Matahari pada Tapak

a. Pergerakan angin terbesar berasal dari arah selatan menuju ke utara (Gambar 7).

b. Pergerakan angin dari barat atau pun dari timur mungkin terjadi, namun intensitasnya lebih sedikit dibanding dari selatan.

6. Analisis Penzoningan Akhir

Tujuan:

Menentukan konsep penzoningan akhir pada bangunan Galeri Mural dan Graffiti yang direncanakan.

Kriteria:

a. Kemudahan akses seluruh pengguna.

b. Setiap fungsi kegiatan memiliki kebutuhan akan privasi dan nilai ekspos yang berbeda-beda.

Hasil:

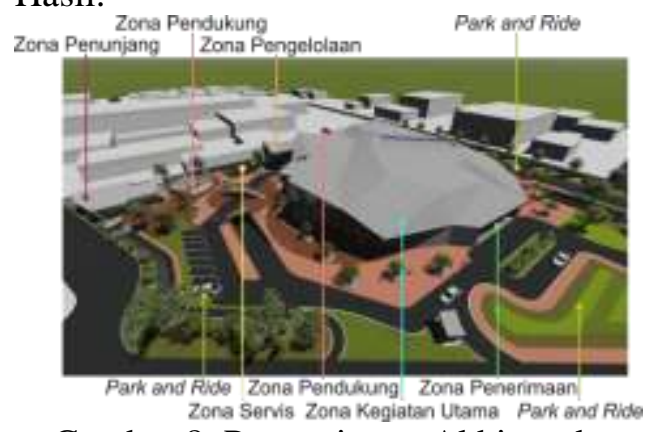

Gambar 8. Penzoningan Akhir pada

Tapak

Hasil dari penzoningan akhir (Gambar 8) dibagi berdasarkan beberapa kegiatan yang ada di dalamnya. Kegiatan tersebut diantaranya:

a. Kegiatan Penerima

Zona ini menjadi area pertama yang dikunjungi sehingga pencapaian harus terlihat jelas dan dekat dengan main entrance di Jalan Ahmad Yani.

b. Kegiatan Utama

Zona ini merupakan tempat berlangsungnya kegiatan pameran, penciptaan karya, diskusi/sharing, 
infomasi, dan workshop serta bersifat publik.

c. Kegiatan Pengelola

Zona ini merupakan zona yang bersifat privat dan semi privat.

d. Kegiatan Pendukung

Zona yang berisi kegiatan yang bersifat publik yang mendukung kegiatan-kegiatan utama pada Galeri Mural dan Graffiti.

e. Kegiatan Penunjang

Zona publik yang memungkinkan untuk pengunjung dapat berkegiatan secara bebas, berupa cafe, open space, dan retail shop.

f. Kegiatan Servis

Zona yang berisi kegiatan yang bersifat pelayanan yang mendukung kegiatan utama.

\section{Analisis Bentuk dan Tatanan}

1. Analisis Massa Bangunan

Tujuan:

Menentukan gubahan massa bangunan sebagai dasar perancangan Galeri Mural dan Graffiti.

\section{Kriteria:}

a. Penempatan massa bangunan sesuai dengan KDB setempat, yakni maksimal $85 \%$.

b. Penempatan massa bangunan berdasarkan zoning fungsi kegiatan.

c. Penempatan massa menyesuaikan dengan kondisi tapak.

\section{Hasil:}

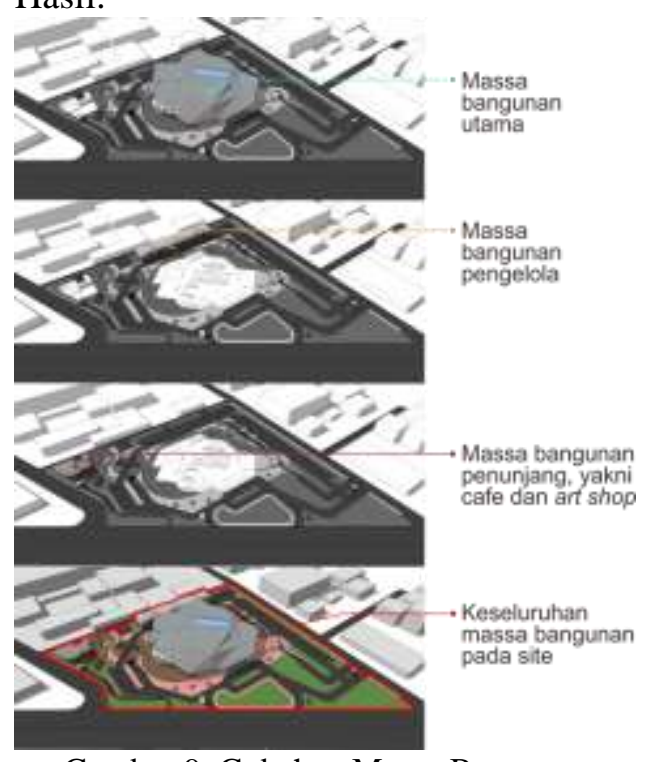

Gambar 9. Gubahan Massa Bangunan
Berdasarkan kriteria tersebut, maka didapat gubahan massa bangunan seperti gambar di atas (Gambar 9). Area penerima serta park and ride merupakan titik awal dari keseluruhan area. Area utama dikelilingi oleh semua area yang ada pada bangunan Galeri Mural dan Graffiti. Area penunjang diletakkan pada tempat yang mudah diakses dan strategis karena memiliki nilai jual tersendiri. Area pendukung diletakkan dekat dengan area utama. Area utilitas diletakkan dibagian paling belakang atau tidak terlihat karena bukan merupakan kegiatan yang perlu diekspos.

\section{Analisis Sirkulasi Bangunan}

Tujuan:

Mendapatkan pola sirkulasi yang dapat memudahkan pengguna dalam melakukan kegiatan di dalam bangunan.

Kriteria:

a. Pola sirkulsi mendukung tampilan eksterior atau fisik bangunan.

b. Meminimalkan terjadinya cross circulation.

c. Kelancaran, kenyamanan, serta kemudahan pengguna dalam mencapai suatu ruang.

\section{Hasil:}

a. Sirkulasi Luar Bangunan

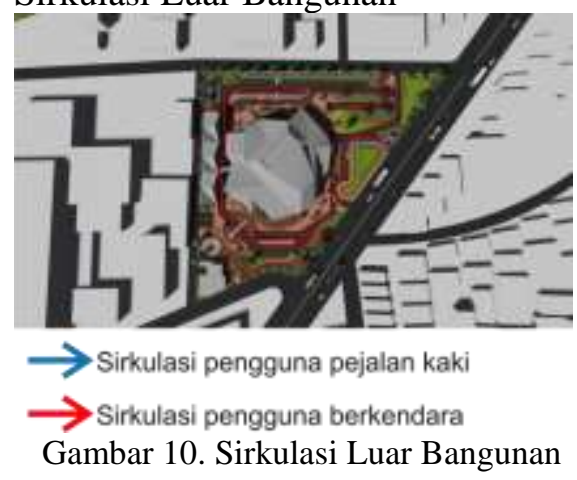

Sirkulasi luar bangunan dibedakan menjadi dua, yakni sirkulasi pejalan kaki atau yang datang dengan transportasi umum dan sirkulasi bagi pengguna yang menggunakan kendaraan pribadi (lihat Gambar 10).

b. Sirkulasi Dalam Bangunan 


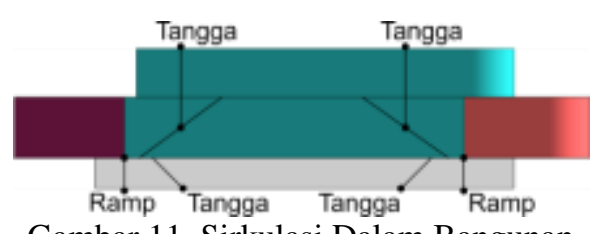

Gambar 11. Sirkulasi Dalam Bangunan

Sirkulasi dalam bangunan pada Galeri Mural dan Graffiti dibedakan menjadi dua sirkulasi vertikal, yakni tangga dan ramp (lihat Gambar 11).

\section{Analisis Bentuk Bangunan}

Tujuan:

Menentukan bentuk bangunan yang digunakan sebagai dasar prancangan galeri mural dan graffiti yang sesuai dengan konsep Ekspresi dalam Arsitektur.

Kriteria:

a. Bentuk yang atraktif, sehingga mudah diingat.

b. Bentuk yang berbeda dengan bangunan sekitar.

c. Bentuk yang asimetris dan dinamis. Hasil:

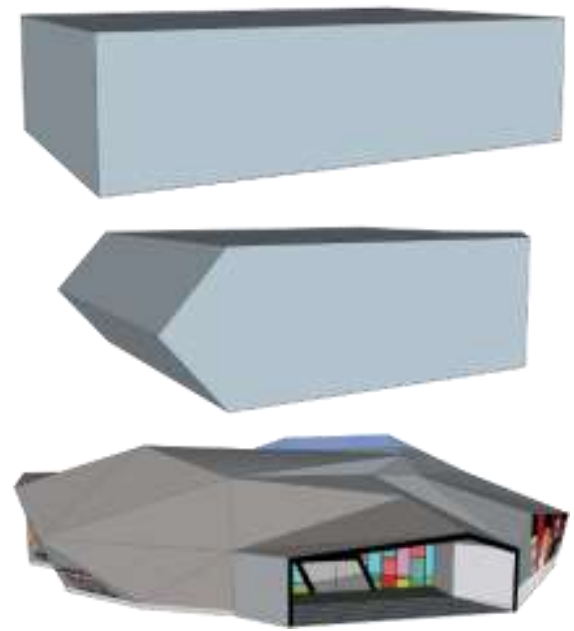

Gambar 12. Bentuk Bangunan

Bentuk bangunan yang atraktif, asimetris dan dinamis, sehingga memberikan efek kontras dari bangunan sekitar yang cenderung kotak dengan sudut lancip. Bentuk-bentuk lengkung yang membuat bangunan lebih dinamis dan atraktif dari bangunan sekitar.

Ekspresi bentuk digunakan pada bangunan ini adalah ekspresi bentuk yang mengungkapkan perpaduan antara perasaan positif (gembira, senang, bahagia, percaya diri, bebas) maupun negatif (sedih, marah, tidak berdaya) melalui pengolahan bentuk bangunan. Bentuk yang digunakan adalah bentuk geometri dasar seperti kotak, kemudian bentuk tersebut diolah dengan penambahan atau pengurangan, yaitu dengan bentuk yang menonjol (ekspresi perasaan senang, atau gembira) maupun bentuk yang tenggelam (ekspresi sedih) pada bagian yang diaplikasikan pada fasad bangunan sehingga dapat menimbulkan tekstur Proses transformasi bentuk dapat dilihat pada Gambar 12.

4. Analisis Material, Finishing, dan Warna Tujuan:

Menentukan penggunaan material, finishing, dan warna yang digunakan sebagai dasar perancangan Galeri Mural dan Graffiti.

Kriteria:

a. Material yang tahan hingga beberapa tahun ke depan.

b. Material tahan terhadap kondisi iklim dan cuaca Indonesia.

c. Menggunakan finishing yang aman bagi kesehatan pengguna.

d. Penggunaan warna yang mencerminkan kaum urban.

e. Menggunakan material yang konstruktif berupa kaca, baja, dan dinding beton atau batu bata.

f. Penggunaan material yang menggunakan bahan material modern mengekspresikan makna modern ataupun urban.

Hasil:

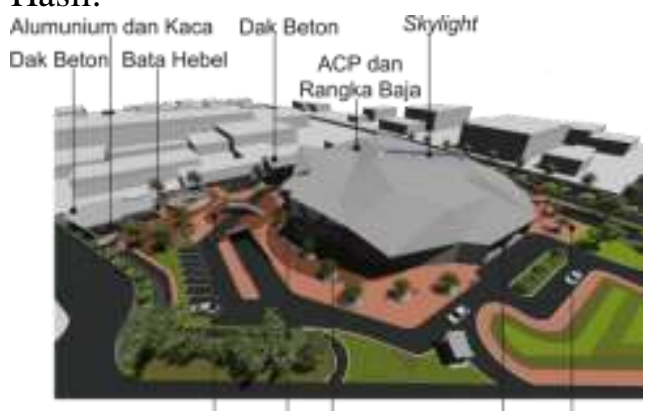

Dek Kayu Kacan Tanpa Finistining Keramik Paving

Gambar 13. Material dan Finishing Bangunan 
Material yang digunakan adalah elemen kombinasi antara kaca, kayu, beton, dan baja sebagai material bangunan (Gambar 13). Pemilihan tersebut didasari dengan alasan beton dapat memperkuat struktur bangunan, kaca dapat menambah efek ringan bangunan sehingga terkesan welcome dan terbuka, baja digunakan sebagai bagian penguat struktur seperti atap bangunan, serta kayu digunakan sebagai ornamen dalam bangunan.

Finishing material dapat menggunakan cat dan beberapa bagian dinding bangunan dapat menggunakan beton ekspos dengan finishing dengan penggunaan coating berwarna clear atau doft. Sedangkan finishing baja, dapat menggunakan lapisan galvalum mengandung unsur alumunium dan zinc sehingga baja yang memiliki siklus hidup hingga ratusan tahun. Sedangkan untuk finishing kayu dapat menggunakan vernis dan anti rayap agar kayu tahan lama.

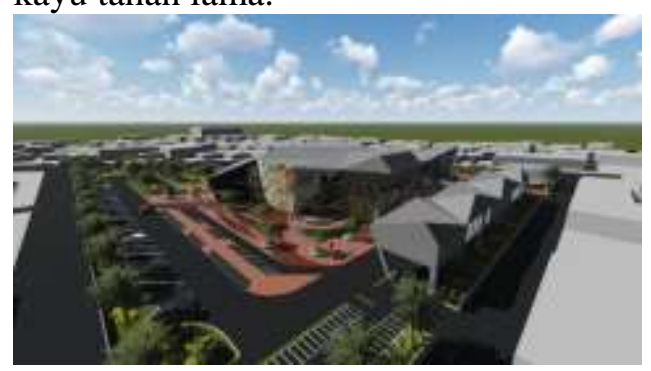

Gambar 14. Warna pada Bangunan

Perwujudan pemilihan warna pada Galeri Mural dan Graffiti ini mengutip dari Janny, Mudeng dan Wahyudi, Siswanto dalam Penerapan Prinsip-Prinsip Seni Ekspresionisme dalam Rancangan Arsitektur, 2012. Pemilihan warna yang mencerminkan kebutuhan kaum urban yang bersifat kekotaan. Pengguna yang merupakan masyarakat yang sibuk, lebih mengarah ke gaya simpel, aktif, dan dinamis. Konsep penerapan warnanya ialah warna-warna seperti warna abu-abu, putih, dan hitam. Warna-warna ini dikombinasikan dengan warna-warna cerah seperti oranye, biru, kuning lemon, ungu, dan sebagainya, namun dengan intensitas yang lebih sedikit dibanding warna abu-abu (Gambar 14), tapi pada interior bangunan dapat menggunakan warna-warna terang karena bangunan ini diperuntukkan bagi mural dan graffiti.

5. Analisis Interior Bangunan

Tujuan:

Menentukan desain interior yang tepat sehingga mampu menunjang konsep ekspresi dalam arsitektur pada Galeri Mural dan Graffiti.

Kriteria:

a. Memberikan nilai estetika pada interior bangunan.

b. Memberi perbedaan skala antara ruang utama dengan ruang penunjang.

\section{Hasil:}

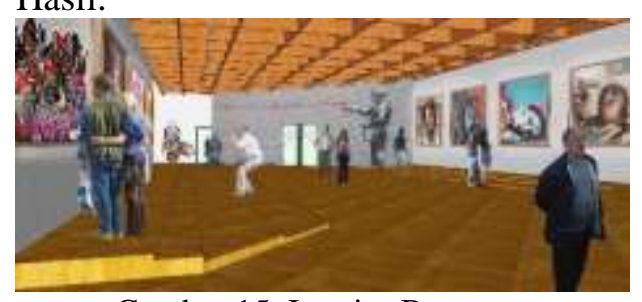

Gambar 15. Interior Bangunan

Hasil dari analisis interior bangunan dapat merujuk pada Gambar 15 dengan elemen hasil analisis sebagai berikut.

a. Plafon

Desain plafon dapat dikombinasikan dengan pencahayaan buatan, membentuk suatu pola sirkulasi tertentu dalam bangunan. Material plafon yang digunakan bervariasi, dapat menggunakan kayu ataupun metal.

b. Dinding

Dinding didesain seaktraktif dan seekspresif mungkin agar menciptakan suasana ruang yang nyaman dan menarik bagi penggunanya. Dinding pada bangunan Galeri Mural dan Graffiti disini dapat berfungsi juga sebagai media pamer selain menggunakan kanvas ataupun kayu triplek. Penggunaan dinding beton ekspos dapan digunakan guna menambah kesan alami pada bangunan.

c. Lantai 
Lantai yang digunakan dapat menunjang sirkulasi dan kenyamanan penggunanya. Penggunaan warna-warna netral dengan beberapa aksen yang tidak terlalu banyak dapat memberikan kenyamanan pengguna.

\section{KESIMPULAN (KONSEP DESAIN)}

Konsep perencanaan dan perancangan Galeri Mural dan Graffiti ini mengacu pada konsep Ekspresi dalam Arsitektur, khususnya diterapkan pada penggunaan makna dari simbol dan ide ruang yang diterapkan dalam bangunan (Gambar 16 dan Gambar 18), perwujudan ekspresi bentuk yang mengungkapkan perasaan postif maupun negatif (Gambar 17), menggunakan material yang konstruktif berupa kaca, baja, dan dinding beton atau batu bata (Gambar 16 dan Gambar 19), serta pemilihan warna pada bangunan (Gambar 17 dan Gambar 20).

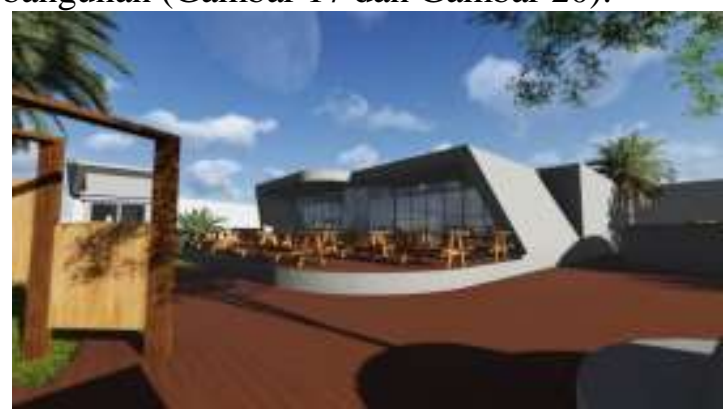

Gambar 16. Area Penunjang

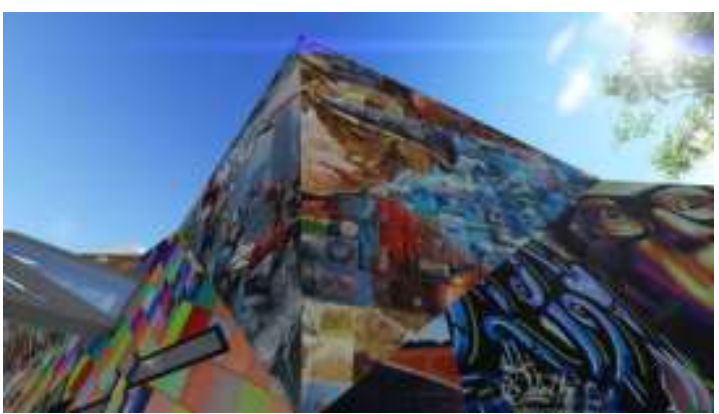

Gambar 17. Fasad Bangunan

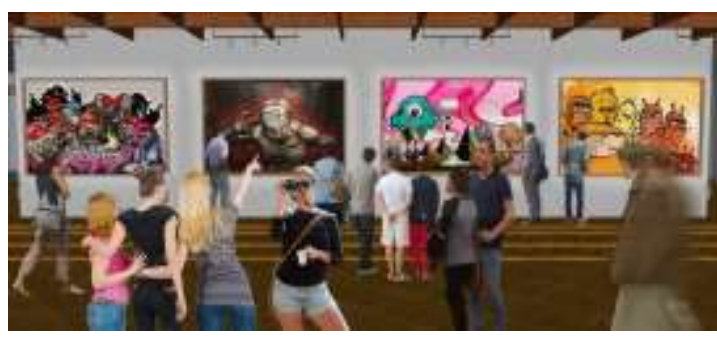

Gambar 18. Interior Bangunan

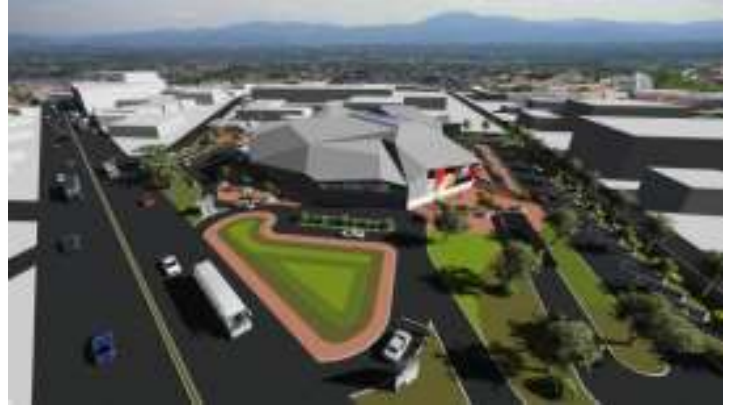

Gambar 19. Eksterior Bangunan

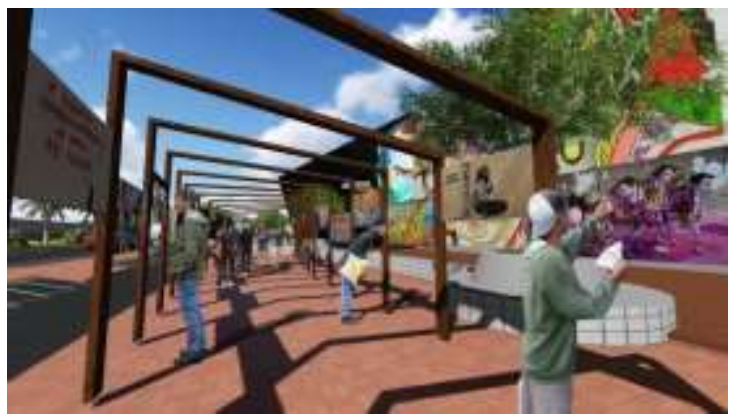

Gambar 20. Eksterior Bangunan

\section{REFERENSI}

Janny, Mudeng dan Wahyudi, Siswanto. 2012.

Prinsip-Prinsip Seni Ekspresionisme dalam Rancangan Arsitektur.

Manado.

Muchamad dan Ikaputra. 2010. Seminar Nasional Metodologi Riset dalam Arsitektur.

RHARHARHA, Andi. 2013. Festival ISAD 2013 "Begins by Connecting, Street Art is Networking". Jakarta: Indonesia Street Art Database.

Perda Kota Surakarta No. 8 Tahun 2009. RTRW Kota Surakarta Tahun 2011-2031. 